\title{
Application of Multi-Objective Optimization by the Utopian Point Method to Determining the Technological Mode of Gac Oil Extraction
}

\author{
Nguyen Tan Dzung
}

\begin{abstract}
The multi-objective optimization problem was built to describe the extraction process of Gac oil by the experimental method. And solving the multi-objective optimization problem determined the optimal Pareto test and the optimal Pareto effect on the technological mode of Gac oil extraction. Experiments were carried out to set up the objective functions describing the influence of technological factors, including solvent volume $\left(Z_{1}, \mathrm{ml} / \mathrm{g}\right)$, time $\left(Z_{2}, h\right)$ and temperature $\left(Z_{3},{ }^{0} C\right)$, on the extraction efficiency $\left(y_{1}, \%\right)$, the loss of $\beta$-Caroten in $\operatorname{Gac}\left(y_{2}, \%\right)$ and the loss of licopene in Gac $\left(y_{3}, \%\right)$. By the application of the utopian point method, the optimal Pareto test was figured out as $\left(Z_{1}{ }^{o p t}=Z_{1} S=15.57 \mathrm{ml} / \mathrm{g}\right.$, $\left.Z_{2}^{\text {opt }}=Z_{2} S=6.056 \mathrm{~h}, Z_{3}{ }^{\text {opt }}=Z_{3} S=69.62^{\circ} \mathrm{C}\right)$, resulting in the optimization technological mode of Gac oil extraction which affected the extraction efficiency reaching the maximum value $\left(y_{1}=y_{1} P S=81.42 \%\right)$, and the loss of $\beta$-Caroten in Gac and licopene in Gac reaching the minimum value (respectively $\mathrm{y}_{2}=$ $\left.y_{2} P S=5.17 \% ; y_{3}=y_{3} P S=5.34 \%\right)$.
\end{abstract}

Index Terms-Optimization, multi-objective optimization, extraction, gac oil.

\section{INTRODUCTION}

Gac is a fruit which has been verified to be rich in essential nutrients, containing many components of carotenoid and lycopene (belong to vitamin A), unsaturated fats, carbohydrates, amino acids, vitamin E, vitamin $\mathrm{Q}$ and other microelements. The $\beta$-carotene and lycopene in Gac oil are twice more than those in liver mackerel and about 10 times more than those in carrots [1]-[3]. Gac is a valuable fruit in the world because it only distributes in Southeast Asia and Southern China. Many studies confirmed the valuable nutriment of Gac [1]-[5], such as the ability to supply $\beta$-carotene and lycopene (vitamin A), vitamin E, vitamin $\mathrm{Q}$, unsaturated fatty acids, and mineral for human.

Currently, Gac has not been popularly used like other fruits, and important nutritional sources of Gac have been untapped effectively. By virtue of a great wealth of vitamin A and unsaturated fatty acids, Gac oil is considered as luxury vegetable oil which owns high economic value. Gac oil has been utilized as a special component in advanced food products and pharmaceutical products. Also in the pharmaceutical industry, Gac oil has been an ingredient for

Manuscript received October, 29, 2011; revised January, 30, 2012. This work was supported in part by the Faculty of Chemical and Food Technology, HCMC University of Technical Education

Nguyen Tan Dzung is from HCM University of Technical Education, 01-Vo Van Ngan Street, Thu Duc District, HCM City, Viet Nam, (e-mail: tandzung072@yahoo.com.vn) the treatment of obesity, heart disease, and hepatitis C. Moreover, in the food industry, Gac oil has been produced as a remarkable vegetable oil consisting of unsaturated fatty acids supporting the anti-cholesterol accumulation [6], [7] The chemical composition of Gac could show in TABLE 1.

TABLE 1: THE CHEMICAL COMPOSITION OF GAC MATERIAL

\begin{tabular}{|c|c|c|c|c|}
\hline \multicolumn{5}{|c|}{ Unit of the chemical composition is g/100g Gac material } \\
\hline Water & Protein & Lipid & Glucid & mineral \\
\hline 74.6 & 2.1 & 15.82 & 7.5 & 0.08 \\
\hline \multicolumn{5}{|c|}{ Unit of vitanins is $\mathrm{mg} \%(\mathrm{mg} / 100 \mathrm{~g} \mathrm{Gac}$ material) } \\
\hline 3-carotene & lycopene & Viatamin E & Vitamin Q & Vitamin C \\
\hline 160.67 & 120.23 & 46.23 & 19.24 & 34.61 \\
\hline
\end{tabular}

In Table 1 was obvious that the $\beta$-carotene, lycopene, lipid, and water content in Gac were very high. In Vietnam, the annual production of $\mathrm{Gac}$ is not popular, but it is only consumed in the form of raw materials. It is also noticeable that the Gac oil extraction has not received sufficient consideration [3]-[7]. The question is to find methods for processing and preservation of $\mathrm{Gac}$ to create valuable products.

According to [6]-[7], the methods of separating oil from Gac were contemporarily classified as two main processes, which were the press extraction and the solvent extraction. For the press method, the extracted oil was shown to be approximately $43.5 \%$ to $48.3 \%$, but with relatively high impurities and water content the refined oil would be brought about the loss of $\beta$-carotene and lycopene in Gac, reducing the quality of the Gac oil [7].

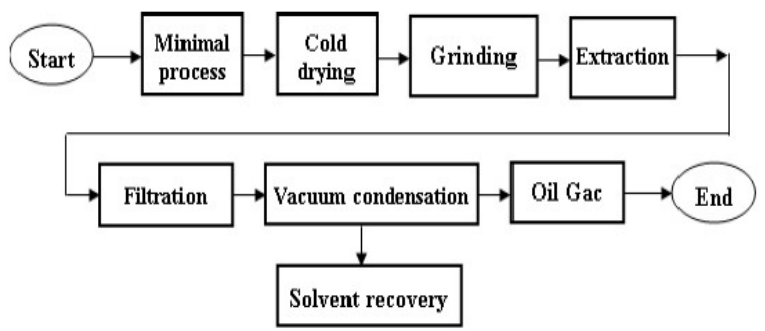

Fig.1. The technological extraction process diagram of GAC oil.

For the solvent method, in order to facilitate the process, the water content should be decreased in advance by the conventional drying method. Due to the high drying temperature (above $100^{\circ} \mathrm{C}$ ), it would cause the loss of $\beta$-carotene, lycopene, and unsaturated fats of Gac oil, which has not been substantiated yet [5]-[7]. On the other hand, the 
solvent extraction of Gac oil primarily investigated the influence of technological factors (solvent volume, time and temperature) on the extraction efficiency whereas the loss of $\beta$-carotene and lycopene, important components characterizing the quality of Gac oil, was not examined [4]-[7].

The technological process shown in Fig. 1 was recommended to explore the problems mentioned. The separated water in Gac was carried out by cold drying method (where low drying temperature limited the loss of $\beta$-carotene, lycopene, and unsaturated fats), and the optimal technological mode of the extraction was established with these parameters, including solvent volume, time and temperature affecting simultaneously the extraction efficiency and the loss of $\beta$-carotene and lycopene [5],[8]. The subjects of extraction process was described as in Fig 2.

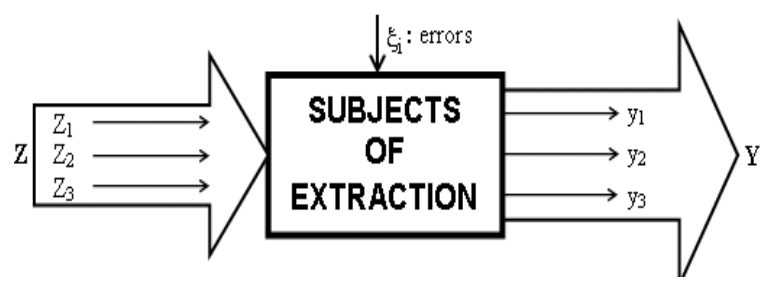

Fig. 2 .Diagram of subjects of extraction process.

It was certain that the extraction was a complicated process. Setting up the optimal technological mode of Gac oil extraction required to determine the following parameters: solvent volume $\left(Z_{1}, \mathrm{ml} / \mathrm{g}\right)$, time $\left(Z_{2}, h\right)$ and temperature $\left(Z_{3}\right.$, ${ }^{0} C$ ), so that the extraction efficiency $\left(y_{l}, \%\right)$ should reach the maximum value, and the loss of $\beta$-carotene $\left(y_{2}, \%\right)$ and lycopene $\left(y_{3}, \%\right)$ should reach the minimum value. The problem was defined as the multi-objective optimization, but particularly every objective function had its own different target, i.e. one reached the maximum value and the other reached the minimum value, encountering difficulties in solving this multi-objective optimization [8]-[10].

According to [8]-[10], there were a number of solutions to the multi-objective optimization problem, namely the linear combination [11], [12], the fuzzy data classification [11], [13], Harrington method [8]-[13], the restricted area method and the utopian point method [8], [9], [14]. In this article, the three-objective optimization problem was solved by the utopian point method with $S(Z)$ optimal combination criteria in order to determine the optimal technological mode of Gac oil extraction.

\section{The Fundamentals of Multi-ObJective OPTIMIZATION}

\section{A. Basic Concepts [8], [9], [14]}

The technological subjects including $m$ objective functions $f_{1}(Z), f_{2}(Z), \ldots, f_{m}(Z)$ form the vector of these functions $f(Z)=$ $\left\{f_{j}(Z)\right\}=\left\{f_{l}(Z), f_{2}(Z), \ldots, f_{m}(Z)\right\}$, where $\mathrm{j}=1$ to $\mathrm{m}$. Every objective function $\mathrm{fj}(Z)$ will be affected by $\mathrm{n}$ variables $Z_{l}$, $Z_{2}, \ldots, Z_{n}$ which form the $Z$ variable vector $Z=\left\{Z_{i}\right\}=\left(Z_{1}\right.$, $Z_{2}, \ldots, Z_{n}$ ), where $\mathrm{i}=1$ to $\mathrm{n}$. These variables vary in the identified domain $\Omega_{Z}$ and the function values form the domain of the objective function $\Omega_{f}$ (in the two-objective optimization problem, the domain can be performed geometrically in the closed curve $A-f(Z)-f(Z S)-B-N-M$ (Fig. 3), [8],[9], [14].

Every objective function $f_{j}(Z)$ with $Z$ variable vector $Z=$ $\left\{Z_{i j}\right\}=\left(Z_{1}, Z_{2}, \ldots, Z_{n}\right)$, where $\mathrm{i}=1$ to $\mathrm{n}$, is considered as the one-objective optimization problem. Hence, the m-objective optimization problem can be simply transformed into the problem to find the minimum value for the set of $\mathrm{m}$ one-objective optimization problems, [8], [9]:

$$
\begin{gathered}
f_{\text {jmin }}=f_{j}\left(Z_{1}^{j \text { opt }}, Z_{2}^{j \text { opt }}, \ldots, Z_{n}^{\text {jopt }}\right) \\
=\operatorname{Min} f_{j}\left(Z_{1}, Z_{2}, \ldots, Z_{n}\right) \\
Z=\left\{Z_{i}\right\}=\left(Z_{1}, Z_{2}, \ldots, Z_{n}\right) \in \Omega_{Z}
\end{gathered}
$$

where $\quad \mathrm{j}=1$ to $\mathrm{m} ; \mathrm{i}=1$ to $\mathrm{n}$

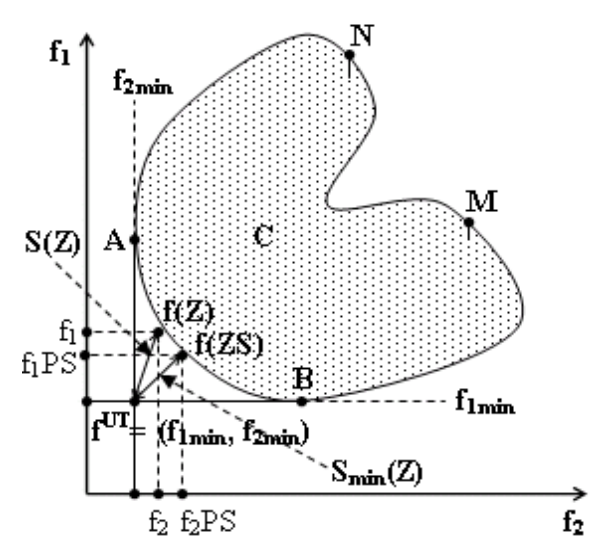

Fig. 3. Dimension of objective functions of the two-objective optimization

The utopian plan and the utopian effect [8], [9]: If the variable vector $Z^{U T}=\left\{Z_{i}^{U T}\right\}=\left(Z_{I}^{U T}, Z_{2}^{U T}, \ldots, Z_{n}^{U T}\right) \in \Omega_{Z}$ is the test for all one-objective optimization problems (1) + (2) + (3), it means that $Z_{i}^{U T}=Z_{i}^{\text {jopt }}$ with $i=1$ to n. Thus, $Z_{i}^{U T}$ is called the utopian plan or the utopian test of the m-objective optimization problem.

In reality, $Z_{i}^{U T}$ does not usually exist because it cannot satisfy all of the targets. However, every one-objective optimization problem $(1)+(2)+(3)$ has its own $f_{\text {jmin }}($ with $j=$ $l$ to $\mathrm{m})$ respectively, so $f^{U T}=\left(f_{l \min }, f_{2 \min }, \ldots, f_{\text {mmin }}\right)$ does exist. Then, $f^{U T}=\left(f_{\text {Imin }}, f_{2 \text { min }}, \ldots, f_{\text {mmin }}\right)$ is called the utopian effect or the utopian point. According to Fig 3, the utopian point $\mathrm{f}^{\mathrm{UT}}$ of the two-objetive optimization problem exists but lies outside the identified domain $\Omega_{\mathrm{f}}$, i.e. the utopian test does not exist.

The dominant plan and the dominated plan [8], [9]: It is assumed that there are two variable vectors $Z Q=\left\{Z Q_{i}\right\}$ and $Z V=\left\{Z V_{i}\right\}$ with $i=1$ to $\mathrm{n}$. Then, there exist respectivly two function vectors $f(Z Q)=\left\{f_{j}(Z Q)\right\}$ and $f(Z V)=\left\{f_{j}(Z V)\right\}$ with $j$ $=1$ to $\mathrm{m}$.

If with all $j: f_{j}(Z Q)<f_{j}(Z V), Z Q$ is called the dominant plan (or the dominant test) over $Z V$, symbolizing: $Z Q$ '> $Z V$; and $Z V$ is called the dominated plan (or the dominated test), symbolizing: $Z V$ ' $<$ ' $Z Q$,

The optimal Pareto plan [8], [9]: The $Z P$ plan is called the optimal Pareto plan in condition that $Z P$ cannot be dominated by any other plans dependable on the identified domain $\Omega_{Z}$. Then, $f(Z P)$ would be called an optimal Pareto effect in the set of the optimal Pareto effects SfP. Fig 3 performs the set of the optimal Pareto effects $\Omega_{\mathrm{f}} \mathrm{P}$ as the curve $A-f(Z)-f(Z S)-B$. 
Theorem 1 (Theorem Pareto): If the multi-objective optimization problem has the test which is the so-called optimal one according to some definition, this test received has to be the optimal Pareto plan without the dependence on the chosen definition, [8]-[15].

Therefore, one test of the multi-objective optimization problem (1) + (2) + (3) found by any method, to be recognized as the optimal by the method chosen, must in advance be certified as the optimal Pareto plan

\section{B. Multi-Objective Optimization By the Utopian Point Method [8], [9]}

Considering the m-objective optimization problem (1) $+(2)$ + (3): The optimal values $f_{\text {Imin }}, f_{2 \min }, \ldots, f_{\text {mmin }}$ can be determined after solving each problems, and the fact that the utopian test (the test for the whole system) does not exist still identifies the utopian point $f^{U T}=\left(f_{\text {lmin }}, f_{2 \min }, \ldots, f_{\text {mmin }}\right)$. A S $(Z)$ optimal combination criterion is defined by the following expression:

$$
S(z)=\sqrt{\left[\sum_{j=1}^{m} s_{j}^{2}(z)\right]}=\sqrt{\left[\sum_{j=1}^{m}\left(f_{j}(z)-f_{j m i n}\right)^{2}\right]}
$$

It is obvious that $\mathrm{S}(Z)$ is the distance from $f(Z)$ to $\mathbf{f}^{\mathrm{UT}}$, where $s_{j}(Z)=f_{j}(Z)-f_{j m i n} /$. Choosing $S(Z)$ optimal combination criterion as an objective function, the m-objective optimization problem are restated as: Find $Z S=$ $\left(Z_{I} S, Z_{2} S, \ldots, Z_{n} S\right) \in \Omega_{Z}$ in order that the objective function $\mathrm{S}(Z)$ reaches the minimum value:

$$
S_{\text {min }}=S(Z S)=\operatorname{Min} S(Z)=\min \left\{\sqrt{\left[\sum_{\mathrm{j}=1}^{\mathrm{m}}\left(\mathrm{f}_{\mathrm{j}}(\mathrm{z})-\mathrm{f}_{\mathrm{j} \min }\right)^{2}\right]}\right\}
$$

$$
Z=\left(Z_{1}, Z_{2}, \ldots, Z_{n}\right) \in \Omega_{Z}
$$

Theorem 2: If ZS of the optimization problem (5) does exist, $\mathrm{ZS}$ is the optimal Pareto test of the m-objective optimization problem (1) + (2) + (3), [8], [9].

Symbol: $f(Z S)=f P S=\left(f_{l} P S, f_{2} P S, \ldots, f_{m} P S\right)$. With the utopian point method (i.e. the m-objective optimization problem convert into the $\mathrm{S}$ optimal combination criterion), the optimal Pareto test ZS will be found to have the optimal Pareto effect $\mathrm{f}(\mathrm{ZS})=\mathrm{fPS}$ closest to the utopian point $f^{U T}=$ $\left(f_{\text {Imin }}, f_{2 \text { min }}, \ldots, f_{\text {mmin }}\right)$. The case $\mathrm{m}=2$ (two objectives) is illustrated in Fig. 3.

\section{MAth MATERIALS AND MEthods}

\section{A. Materials}

- The materials used for the extraction experiments were mature Gac, mainly grown in Tay Nguyen area and Southeastern area of Vietnam [1], [2].

- Before the extraction, the Gac were cold-dried until they reached the residual water content of $7.45 \%,[1],[2]$.

- Etanol was used as solvent for the extraction of Gac oil, which was considered more appropriate than hecxan, acetone and diethyl ether [6], [7].

\section{B. Apparatus}

- Satoriusbasic Type BA310S was used to determine the weight of samples with the range of 0 to $300 \mathrm{~g}$ and the error of $0.1 \mathrm{~g}$.

- Cylinders were used to examine the volume of etanol with the range of 0 to $500 \mathrm{ml}$ and the error of $0.1 \mathrm{~g}$.

- Dual digital thermometer (T.P.34-23) was used to determine the temperature of solvent and samples during the extraction with the range of 0 to $100^{\circ} \mathrm{C}$ and the error of $0.5^{\circ} \mathrm{C}$. A timer was used to examine the extraction time.

- The cold drying system DSL-P-V-01 controlled by PLC was used to dry Gac (Fig 4a) [16], [17].

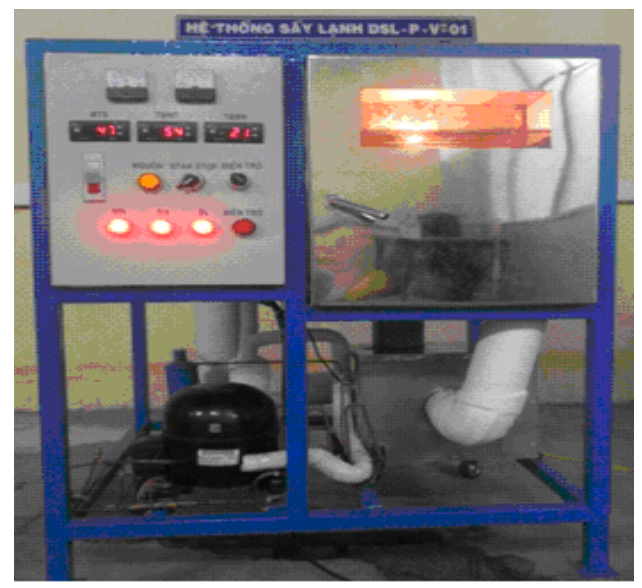

Fig. 4a. The system cold drying DSL-P-V-01.

- The vacuum condense machine controlled by computer was used to recover etanol (Fig 4b).

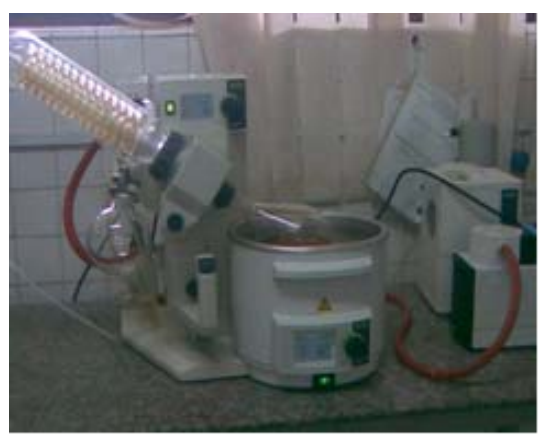

Fig. 4b. The equipment of vacuum condense.

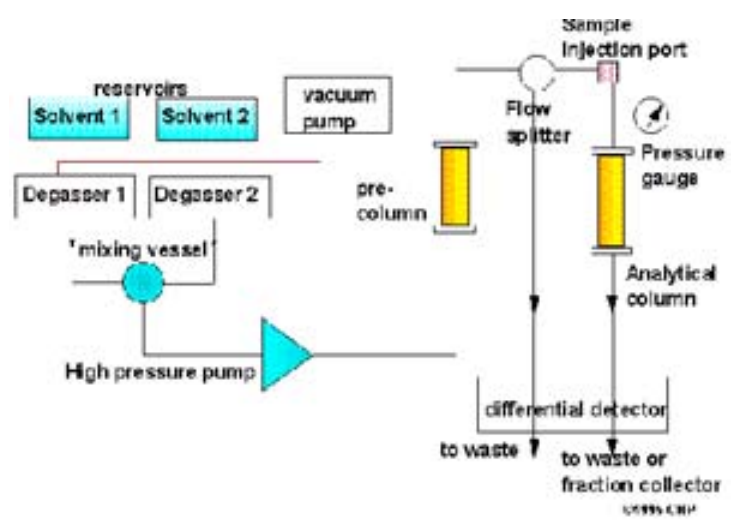

Fig. 4c. The diagram principle of the system of HPLC. 
- The equipments of High Performance Liquid Chromatography (HPLC) were used to determine the content of $\beta$-carotene and lycopene of Gac oil. These equipments could be seen in Fig 4c and Fig 4d.

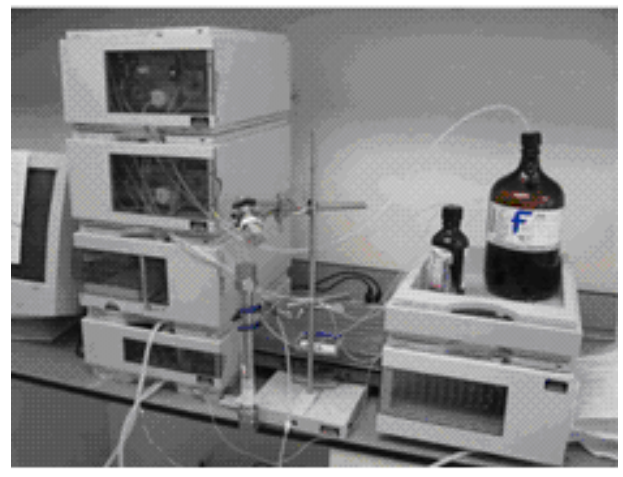

Fig. 4d. The system of HPLC.

\section{Methods}

Determining the extraction efficiency $\left(y_{l}, \%\right)$ : the extraction efficiency of Gac oil was defined as the ratio of the weight of the extracted oil and the weight of the total oil in the initial Gac [3]-[18].

$$
\mathrm{y}_{1}=\frac{\mathrm{m}_{\mathrm{oil} 2}}{\mathrm{~m}_{\mathrm{oill}}} \cdot 100 \%
$$

where: $y_{1}-$ the extraction efficiency of etanol, $\% ; m_{o i l}-$ the weight of the total oil in the $10 \mathrm{~g}$ initial the cold-dried Gac, g; $m_{\text {oil }}-$ the weight of the extracted oil from the $10 \mathrm{~g}$ the cold-dried Gac, g.

The maximum extraction efficiency $\left(y_{1 \max }\right)$ is $100 \%$. However, experimental extraction efficiency was always lower than $100 \%\left(y_{1}<100 \%\right)$.

Determining the loss of $\beta$-carotene of the product $\left(y_{2}, \%\right)$ : HPLC method in TCVN [1], [3], [18].

$$
\mathrm{y}_{2}=\frac{\mathrm{m}_{1}-\mathrm{m}_{2}}{\mathrm{~m}_{1}} 100 \%=\frac{\Delta \mathrm{m}}{\mathrm{m}_{1}} 100 \%
$$

where: $y_{2}$ - the loss of $\beta$-carotene after extraction, $\% ; \mathrm{m}_{1}-$ the content of $\beta$-carotene in the initial the cold-dried $\mathrm{Gac}, \mathrm{mg} \%$; $\mathrm{m}_{2}$ - the content of $\beta$-carotene in the cold-dried Gac after extraction, $\mathrm{mg} \%$ (Fig $4 \mathrm{e})$.

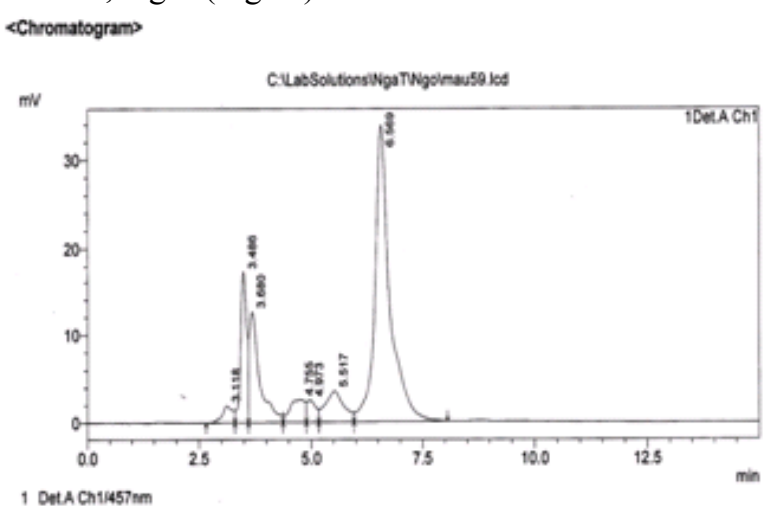

Fig. $4 \mathrm{e}$. The chromatograph of $\beta$-carotene on HPLC.

Determining the loss of lycopene of the product $\left(\mathrm{y}_{2}, \%\right)$ : HPLC method in TCVN [1], [3], [18].

$$
\mathrm{y}_{3}=\frac{\mathrm{m}_{\mathrm{a}}-\mathrm{m}_{\mathrm{b}}}{\mathrm{m}_{\mathrm{a}}} 100 \%=\frac{\Delta \mathrm{m}}{\mathrm{m}_{\mathrm{a}}} 100 \%
$$

where: $y_{3}-$ the loss of lycopene after extraction, $\% ; \mathrm{m}_{\mathrm{a}}-$ the content of lycopene in the initial the cold-dried Gac, $\mathrm{mg} \%$; $\mathrm{m}_{\mathrm{b}}$ - the content of lycopene in the cold-dried Gac after extraction, $\mathrm{mg} \%$ (Fig $4 \mathrm{f}$ ).

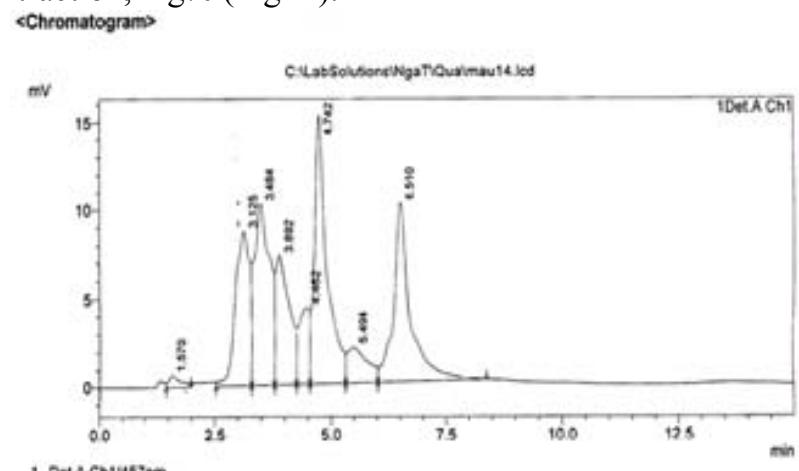

Fig. 4f. The chromatograph of lycopene on HPLC.

The fact that the product achieves the best quality means $y_{2 \min }=0$ and $\mathrm{y}_{3 \min }=0$. In fact, $\mathrm{y}_{2}>0$ and $\mathrm{y}_{3}>0$.

- Orthogonal experimental planning method with degree $2[1,8]$.

- Establishing and solving 3-objective optimization problem by the utopian point method [8]- [14].

\section{RESUlts AND Discussion}

\section{A. Establishing the Constituent Objective Functions of the Multi-Objective Problem}

The constituent objective functions of Gac oil extraction $\left(y_{1}, y_{2}\right.$ and $\left.y_{3}\right)$ depended on the parameters, including: solvent volume $\left(Z_{1}, \mathrm{ml} / \mathrm{g}\right)$, time $\left(Z_{2}, h\right)$ and temperature $\left(Z_{3},{ }^{0} \mathrm{C}\right)$. The experimental results showed that the extraction efficiency $\left(y_{1}, \%\right)$, the loss of $\beta$-carotene $\left(y_{2}, \%\right)$ and lycopene $\left(y_{3}, \%\right)$ related to $Z_{1}, Z_{2}, Z_{3}$ with orthogonal degree 2 . Therefore, the objective functions $y_{1}, y_{2}$ and $y_{3}$ were described by the experimental planning method with the degree- 2 orthogonal experimental matrix. The experimental number is determined as [8]-[13]:

$$
N=n_{k}+n_{*}+n_{0}=2^{k}+2 k+n_{0}=25
$$

where: $k=3 ; n_{k}=2^{k}=2^{3}=8 ; n_{*}=2 k=2.3=6 ; n_{0}=4$, carrying out 25 experiments.

These variables $x_{1}, x_{2}, x_{3}$ were coded variables of $\mathrm{Z}_{1}, \mathrm{Z}_{2}, \mathrm{Z}_{3}$ by the following expression [8]-[13]:

$$
x_{j}=\left(Z_{j}-Z_{j}^{0}\right) / \Delta Z_{j}
$$

where: $Z_{j}^{0}=\left(Z_{j}^{\max }+Z_{j}^{\min }\right) / 2 ; \quad \Delta Z_{j}=\left(Z_{j}^{\max }-Z_{j}^{\min }\right) / 2$;

$$
Z_{j}^{\min } \leq Z_{j} \leq Z_{j}^{\max }
$$

The value of the star point [8]:

$$
\alpha=\sqrt{\sqrt{\mathrm{N} .2^{(\mathrm{k}-2)}}-2^{(\mathrm{k}-1)}}=1.414
$$

And conditions of the orthogonal matrix $[8,9,13]$ :

$$
\lambda=\frac{1}{\mathrm{~N}}\left(2^{\mathrm{k}}+2 \alpha^{2}\right)=2 / 3
$$

The mathematical model of objective functions is defined by the following expression[8]-[13]: 


$$
y=b_{0}+\sum_{j=1}^{k} b_{j} x_{j}+\sum_{j \neq i ; j=1}^{k} b_{j i} x_{j} x_{i}+\sum_{j=1}^{k} b_{j j} x_{j}^{2}
$$

The experimental conditions established the parameter levels affecting the process of extraction oil Gac shown in TABLE 1 .

\section{1) Establishing the mathematical model of objective}

functions $y_{1}, y_{2}$ and $y_{3}$

The experiments were carried out with all of the parameter levels in Table 2 to determine the value of the objective functions $y_{1}, y_{2}$ and $y_{3}$. The results were summarized in Table
3.

TABLE 2: PARAMETER LEVEL DESIGN

\begin{tabular}{|l|c|c|c|c|c|c|}
\hline \multirow{2}{*}{$\begin{array}{l}\text { Parameter } \\
\mathrm{s}\end{array}$} & \multicolumn{5}{|c|}{ Levels } & $\begin{array}{c}\text { Deviatio } \\
\mathrm{n}\end{array}$ \\
\cline { 2 - 7 } & $\begin{array}{c}-\alpha \\
(-1.414)\end{array}$ & $\begin{array}{c}\text { Low } \\
-1\end{array}$ & $\begin{array}{c}\text { Central } \\
0\end{array}$ & $\begin{array}{c}\text { High } \\
+1\end{array}$ & $\begin{array}{c}+\alpha \\
(1.414)\end{array}$ & $\Delta \mathrm{Z}_{\mathrm{i}}$ \\
\hline $\mathrm{Z}_{1},(\mathrm{ml} / \mathrm{g})$ & 8.35 & 10 & 14 & 18 & 19.66 & 4 \\
\hline $\mathrm{Z}_{2},(\mathrm{~h})$ & 1.172 & 2 & 4 & 6 & 6.828 & 2 \\
\hline $\mathrm{Z}_{3},\left({ }^{0} \mathrm{C}\right)$ & 38.79 & 45 & 60 & 75 & 81.21 & 15 \\
\hline
\end{tabular}

TABLE 3: The DEgREe-2 ORthogOnAl ExPERIMENTAL MATRIX, $\mathrm{K}=3, \mathrm{~N}_{0}=4$

\begin{tabular}{|c|c|c|c|c|c|c|c|c|c|c|c|c|c|c|}
\hline \multicolumn{2}{|c|}{$\mathrm{N}$} & $\mathrm{x}_{0}$ & $\mathrm{x}_{1}$ & $\mathrm{x}_{2}$ & $\mathrm{x}_{3}$ & $\mathrm{x}_{1} \mathrm{x}_{2}$ & $\mathrm{x}_{1} \mathrm{x}_{3}$ & $\mathrm{x}_{2} \mathrm{x}_{3}$ & $x_{1}^{2}-2 / 3$ & $x_{2}^{2}-2 / 3$ & $x_{3}^{2}-2 / 3$ & $\mathrm{y}_{1}$ & $y_{2}$ & $\mathrm{y}_{3}$ \\
\hline \multirow{8}{*}{$2^{\mathrm{k}}$} & 1 & 1 & 1 & 1 & 1 & 1 & 1 & 1 & 0.333 & 0.333 & 0.333 & 82.80 & 5.496 & 5.889 \\
\hline & 2 & 1 & -1 & 1 & 1 & -1 & -1 & 1 & 0.333 & 0.333 & 0.333 & 80.17 & 6.12 & 6.557 \\
\hline & 3 & 1 & 1 & -1 & 1 & -1 & 1 & -1 & 0.333 & 0.333 & 0.333 & 79.11 & 6.248 & 6.694 \\
\hline & 4 & 1 & -1 & -1 & 1 & 1 & -1 & -1 & 0.333 & 0.333 & 0.333 & 75.32 & 5.408 & 5.794 \\
\hline & 5 & 1 & 1 & 1 & -1 & 1 & -1 & -1 & 0.333 & 0.333 & 0.333 & 78.28 & 6.272 & 6.72 \\
\hline & 6 & 1 & -1 & 1 & -1 & -1 & 1 & -1 & 0.333 & 0.333 & 0.333 & 64.96 & 4.672 & 5.006 \\
\hline & 7 & 1 & 1 & -1 & -1 & -1 & -1 & 1 & 0.333 & 0.333 & 0.333 & 70.43 & 4.504 & 4.826 \\
\hline & 8 & 1 & -1 & -1 & -1 & 1 & 1 & 1 & 0.333 & 0.333 & 0.333 & 79.44 & 6.344 & 6.797 \\
\hline \multirow{5}{*}{$2 \mathrm{k}$} & 9 & 1 & 1.414 & 0 & 0 & 0 & 0 & 0 & 1.333 & -0.667 & -0.667 & 75.57 & 6.104 & 6.54 \\
\hline & 10 & 1 & -1.414 & 0 & 0 & 0 & 0 & 0 & 1.333 & -0.667 & -0.667 & 68.18 & 6.224 & 6.669 \\
\hline & 11 & 1 & 0 & 1.414 & 0 & 0 & 0 & 0 & -0.667 & 1.333 & -0.667 & 77.21 & 4.624 & 4.954 \\
\hline & 12 & 1 & 0 & -1.414 & 0 & 0 & 0 & 0 & -0.667 & 1.333 & -0.667 & 72.71 & 5.512 & 5.906 \\
\hline & 13 & 1 & 0 & 0 & 1.414 & 0 & 0 & 0 & -0.667 & -0.667 & 1.333 & 75.59 & 4.76 & 5.1 \\
\hline \multirow{4}{*}{$\mathrm{n}_{0}$} & 15 & 1 & 0 & 0 & 0 & 0 & 0 & 0 & -0.667 & -0.667 & -0.667 & 78.72 & 5.952 & 6.377 \\
\hline & 16 & 1 & 0 & 0 & 0 & 0 & 0 & 0 & -0.667 & -0.667 & -0.667 & 80.94 & 5.896 & 6.317 \\
\hline & 17 & 1 & 0 & 0 & 0 & 0 & 0 & 0 & -0.667 & -0.667 & -0.667 & 82.17 & 6.208 & 6.651 \\
\hline & 18 & 1 & 0 & 0 & 0 & 0 & 0 & 0 & -0.667 & -0.667 & -0.667 & 79.49 & 5.832 & 6.249 \\
\hline
\end{tabular}

The mathematical model of regression equations $(14,15$ and 16) were obtained after processing the experimental data, calculating the coefficients, testing the significance of the coefficients by the Student test, and testing the regression equations for the fitness of the experimental results by Fisher test [8]:

$$
\begin{aligned}
y_{1}=76.1+ & 3.582 x_{1}+2.6 x_{3} \\
- & 1.99 x_{1} x_{3}-1.912\left(x_{1}{ }^{2}-2 / 3\right) \\
& -0.37\left(x_{2}{ }^{2}-2 / 3\right)-1.94\left(x_{3}{ }^{2}-2 / 3\right) \\
y_{2}=5.6+ & 0.27 x_{1}-0.27 x_{2} \\
+ & 0.17 x_{3}-0.4 x_{1} x_{3}+0.3\left(x_{1}{ }^{2}-2 / 3\right) \\
& -0.24\left(x_{2}{ }^{2}-2 / 3\right)-0.43\left(x_{3}{ }^{2}-2 / 3\right) \\
y_{3}=6.1+ & 0.28 x_{1}-0.29 x_{2}+0.18 x_{3} \\
- & 0.43 x_{1} x_{3}-0.15 x_{2} x_{3}+0.33\left(x_{1}{ }^{2}-2 / 3\right) \\
& -0.255\left(x_{2}{ }^{2}-2 / 3\right)-0.46\left(x_{3}{ }^{2}-2 / 3\right)
\end{aligned}
$$

\section{1) Establishing the mathematical model of}

\section{multi-objective functions}

The technological parameters $\left(\mathrm{x}_{1}, \mathrm{x}_{2}\right.$ and $\left.\mathrm{x}_{3}\right)$ of the extraction had the simultaneous impact on these objective functions $\left(y_{1}, y_{2}\right.$ and $\left.y_{3}\right)$ with the identified domain $\Omega_{x}=$ $\left\{-1.414 \leq x_{1}, x_{2}, x_{3} \leq 1.414\right\}$. Thus, the mathematical model of three-objective optimization problem determining the technological mode of Gac oil extraction was restated as: Finding in common the test $x=\left(x_{1}{ }^{o p t}, x_{2}{ }^{o p t}, x_{3}{ }^{o p t}\right) \in \Omega_{x}=$ $\left\{-1.414 \leq x_{1}, x_{2}, x_{3} \leq 1.414\right\}$ in order that:

$$
\left\{\begin{array}{l}
\mathrm{y}_{1}=\mathrm{f}_{1 \mathrm{max}}\left(\mathrm{x}_{1}{ }^{\mathrm{opt}}, \mathrm{x}_{2}{ }^{\mathrm{opt}}, \mathrm{x}_{3}{ }^{\mathrm{opt}}\right)=\max \mathrm{f}_{1}\left(\mathrm{x}_{1}, \mathrm{x}_{2}, \mathrm{x}_{3}\right) \\
\mathrm{y}_{2}=\mathrm{f}_{2 \min }\left(\mathrm{x}_{1}{ }^{\mathrm{opt}}, \mathrm{x}_{2}{ }^{\mathrm{opt}}, \mathrm{x}_{3}{ }^{\mathrm{opt}}\right)=\min \mathrm{f}_{2}\left(\mathrm{x}_{1}, \mathrm{x}_{2}, \mathrm{x}_{3}\right) \\
\mathrm{y}_{3}=\mathrm{f}_{3 \min }\left(\mathrm{x}_{1}{ }^{\mathrm{opt}}, \mathrm{x}_{2}{ }^{\mathrm{opt}}, \mathrm{x}_{3}{ }^{\mathrm{opt}}\right)=\min \mathrm{f}_{3}\left(\mathrm{x}_{1}, \mathrm{x}_{2}, \mathrm{x}_{3}\right) \\
\forall \mathrm{x}=\left(\mathrm{x}_{1}, \mathrm{x}_{2}, \mathrm{x}_{3}\right) \in \Omega_{\mathrm{x}}
\end{array}\right.
$$

This was the multi-objective optimization problem in which the equations of the whole system (17) did not reach the same destination, i.e. one objective function towards the maximum value and the other objective functions towards the minimum value. Therefore, it was necessary that the multi-objective optimization problem (17) be modified in order that all of the objective functions should attain the minimum value as the followings:

$$
\begin{aligned}
& I_{1}(x)=I_{1}\left(x_{1}, x_{2}, x_{3}\right)=100-y_{1}=100-f_{1}\left(x_{1}, x_{2}, x_{3}\right) \\
& I_{2}(x)=I_{2}\left(x_{1}, x_{2}, x_{3}\right)=y_{2}=f_{2}\left(x_{1}, x_{2}, x_{3}\right) \\
& I_{3}(x)=I_{3}\left(x_{1}, x_{2}, x_{3}\right)=y_{3}=f_{3}\left(x_{1}, x_{2}, x_{3}\right)
\end{aligned}
$$

With $0 \leq \mathrm{y}_{1} \leq 100 \%$, consequently $0 \leq \mathrm{I}_{1}(\mathrm{x}) \leq 100 \%$; if $\mathrm{y}_{1}(\mathrm{x})$ $=y_{1 \max }(x), I_{1}(x)=I_{1 \min }(x)$. Because all targets of the objective 
functions (18), (19) and (20) were to find the minimum value, the multi-objective optimization problem was restated as: Finding in common the test $\mathrm{x}=\left(\mathrm{x}_{1}{ }^{\text {opt }}, \mathrm{x}_{2}{ }^{\text {opt }}, \mathrm{x}_{3}{ }^{\text {opt }}\right) \in \Omega_{\mathrm{x}}=$ $\left\{-1.414 \leq \mathrm{x}_{1}, \mathrm{x}_{2}, \mathrm{x}_{3} \leq 1.414\right\}$ in order that:

$$
\left\{\begin{array}{l}
\mathrm{I}_{1}=\mathrm{I}_{1 \min }\left(\mathrm{x}_{1}{ }^{\mathrm{opt}}, \mathrm{x}_{2}{ }^{\mathrm{opt}}, \mathrm{x}_{3}{ }^{\mathrm{opt}}\right)=\min \left\{\mathrm{I}_{1}\left(\mathrm{x}_{1}, \mathrm{x}_{2}, \mathrm{x}_{3}\right)\right\} \\
\mathrm{I}_{2}=\mathrm{I}_{2 \min }\left(\mathrm{x}_{1}{ }^{\mathrm{opt}}, \mathrm{x}_{2}{ }^{\mathrm{opt}}, \mathrm{x}_{3}{ }^{\mathrm{opt}}\right)=\min \left\{\mathrm{I}_{2}\left(\mathrm{x}_{1}, \mathrm{x}_{2}, \mathrm{x}_{3}\right)\right\} \\
\mathrm{I}_{3}=\mathrm{I}_{3 \min }\left(\mathrm{x}_{1}{ }^{\mathrm{opt}}, \mathrm{x}_{2}{ }^{\mathrm{opt}}, \mathrm{x}_{3}{ }^{\mathrm{opt}}\right)=\min \left\{\mathrm{I}_{3}\left(\mathrm{x}_{1}, \mathrm{x}_{2}, \mathrm{x}_{3}\right)\right\} \\
\forall \mathrm{x}=\left(\mathrm{x}_{1}, \mathrm{x}_{2}, \mathrm{x}_{3}\right) \in \Omega_{\mathrm{x}}
\end{array}\right.
$$

\section{B. Solving the one-Objective Optimization Problems}

These one-objective optimization problems were found to achieve: $I_{1 \min }=\operatorname{minI}_{1}\left(x_{1}, x_{2}, x_{3}\right) ; I_{2 \min }=\min _{2}\left(x_{1}, x_{2}, x_{3}\right) ; I_{3 \min }$ $=\operatorname{minI}_{3}\left(x_{1}, x_{2}, x_{3}\right)$, with the identified domain $\Omega_{x}=\left\{-1 \leq x_{1}\right.$, $\left.x_{2}, x_{3} \leq 1\right\}$. By the meshing method programmed in Matlab 7.0 , the results of the optimal parameters of every objective function (18), (19) and (20) limited in the experimental domain were summarized in TABLE 4.

TABLE 4: MinimuM TESTS OF EACH ONE-OBJECTIVE OPTIMIZATION PROBLEM

\begin{tabular}{|c|c|c|c|c|c|}
\hline $\begin{array}{c}\text { Extraction } \\
\text { material }\end{array}$ & $\mathrm{j}$ & $\mathrm{I}_{\mathrm{jmin}}$ & $\mathrm{x}_{1}{ }^{\mathrm{j} \text { opt }}$ & $\mathrm{x}_{2}{ }^{\mathrm{j} \text { opt }}$ & $\mathrm{x}_{3}{ }^{\mathrm{j} \text { opt }}$ \\
\hline \multirow{3}{*}{$\mathrm{Gac}$} & 1 & 19.31 & 0.802 & 0.000 & 0.259 \\
\cline { 2 - 6 } & 2 & 3.303 & -1.393 & 1.414 & -1.414 \\
\cline { 2 - 6 } & 3 & 3.965 & -1.345 & 1.414 & -1.414 \\
\hline
\end{tabular}

According to the Table 4, the utopian points were indentified: $I^{U T}=\left(I_{1 \min }, I_{2 \min }, I_{3 \min }\right)=(19.31,3.303$, and 3.965). However, the utopian plan did not exist, because of $\mathrm{x}^{\mathrm{jopt}}=\left(x_{1}{ }^{\text {jopt }}, x_{2}{ }^{\text {jopt }}, x_{3}{ }^{\text {jopt }}\right) \neq x^{\text {kopt }}=\left(x_{1}{ }^{k o p t}, x_{2}{ }^{k o p t}, x_{3}{ }^{k o p t}\right)$ where $\mathrm{j}, k$ $=1$ to 3 , and $j \neq k$.

\section{Solving the Multi-Objective Optimization Problem by the Utopian Point Method}

The purpose of the experiment was to reach the targets of the extraction of Gac oil which were expressed by 3 regression equations (18), (19) and (20), but the tests satisfying all function values $\left(\mathrm{I}_{1 \min }, \mathrm{I}_{2 \min }, \mathrm{I}_{3 \min }\right)$ could not be found. Hence, the idea of the three-objective optimization problem was to find the optimal Pareto test for the optimal Pareto effect $\mathrm{I}(\mathrm{xS})=\mathrm{IPS}=\left(\mathrm{I}_{1} \mathrm{PS}, \mathrm{I}_{2} \mathrm{PS}, \mathrm{I}_{3} \mathrm{PS}\right)$ closest to the utopian point $\mathrm{I}^{\mathrm{UT}}=\left(\mathrm{I}_{1 \min }, \mathrm{I}_{2 \min }, \mathrm{I}_{3 \min }\right)=(19.31,3.303,3.965)$.

Establishing the S-objective combination function $\mathrm{S}\left(I_{l}\right.$, $\left.I_{2}, I_{3}\right)=S\left(x_{1}, x_{2}, x_{3}\right)=S(x)$ as the followings:

$$
\left\{\begin{array}{l}
S\left(x_{1}, x_{2}, x_{3}\right)=\sqrt{\sum_{j=1}^{3}\left(I_{j}-I_{j m i n}\right)^{2}} \\
\Omega_{x}=\left\{-1.414 \leq x_{1}, x_{2}, x_{3} \leq 1.414\right\}
\end{array}\right.
$$

The three-objective optimization problem needed to indentify $x S=\left(x_{1} S, x_{2} S, x_{3} S\right) \in \Omega_{\mathrm{x}}$ in order that $S\left(x_{1} S, x_{2} S, x_{3} S\right)$ $=\operatorname{Min}\left\{S\left(x_{1}, x_{2}, x_{3}\right)\right\}$. The minimum value of (22) was determined by the meshing method programmed in Matlab 7.0:

$$
S_{\text {min }}=\operatorname{Min}\left\{S\left(x_{1}, x_{2}, x_{3}\right)\right\}=2.726
$$

With: $\quad x_{1} S=0.393 ; x_{2} S=1.014 ; \quad x_{3} S=0.642$;

Then, transforming into real variables:

$$
Z_{1}^{o p t}=15.57 \mathrm{ml} / \mathrm{g} ; Z_{2}^{o p t}=6.056 \mathrm{~h} ; Z_{3}^{o p t}=69.62{ }^{0} \mathrm{C}
$$

Substituting $x_{1} R, x_{2} R, x_{3} R$ into these equations (18), (19) and (20), the optimal Pareto effect was obtained as: $I_{1} P S=$ $19.98 ; I_{2} P S=5.31 ; I_{3} P S=5.68$

Similarly, substituting $x_{1} R, x_{2} R, x_{3} R$ into these equations (14), (15) and (16), the optimal Pareto effect was obtained as: $y_{1} P S=80.02 ; y_{2} P S=5.31 ; y_{3} P S=5.68$

By the utopian point method, solving the multi-objective optimization problem with S-Optimal combination criterion which satisfied the minimum S-Optimal combination criterion $\left(S_{\min }=2.726\right)$ were determined the optimal Pareto test (or the technological mode of Gac oil extraction) as: the solvent volume of the extraction was $Z_{I}^{o p t}=15.57 \mathrm{ml} / \mathrm{g}$, the extraction time was $Z_{2}{ }^{\text {opt }}=6.056 \mathrm{~h}$, and the extraction temperature was $Z_{3}^{\text {opt }}=69.62^{0} \mathrm{C}$. Corresponding with the optimal Pareto test will be the optimal Pareto effect as: the extraction efficiency of Gac oil was $y_{1} P S=80.02 \%$; the loss of $\beta$-carotene of the Gac oil was $y_{2} P R=5.31 \%$ and the loss of lycopene of the Gac oil was $y_{3} P R=5.68 \%$.

Compared with the experimental results from the table 3 , these results above were suitable and satisfying with the objectives of the problem.

\section{Experiment to Test the Results of Multi-Objective Optimization Problem}

Carrying out the extraction of Gac oil at the optimal Pareto test: the solvent volume of the extraction of $Z_{1}{ }^{\text {opt }}=15.57 \mathrm{ml} / \mathrm{g}$, the extraction time of $Z_{2}^{o p t}=6.056$ hours, and the extraction temperature of $Z_{3}{ }^{\text {opt }}=69.62{ }^{0} \mathrm{C}$, the experimental results were determined as: the extraction efficiency of avocado oil of $y_{1}=$ $81.42 \%$, the loss of $\beta$-carotene of the Gac oil of $y_{2}=5.17 \%$ and the loss of lycopene of the Gac oil of $y_{3}=5.34 \%$.

Consequently, it was very noticeable that the results from the optimization problems of the extraction process had the approximation to the experimental results.

After oil Gac was separated by the extraction method at the optimal Pareto test: $Z_{1}^{o p t}=15.57 \mathrm{ml} / \mathrm{g} ; Z_{2}^{o p t}=6.056$ hours; $Z_{3}{ }^{\text {opt }}=69.62^{\circ} \mathrm{C}$. The finished product obtained could be seen in Fig 5.

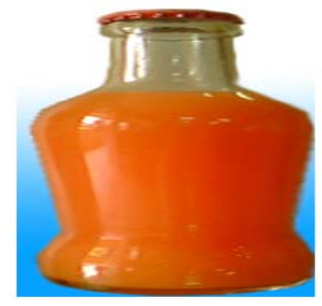

Fig. 5. The oil was extracted from Gas.

It was certain that the optimal Pareto test and the optimal Pareto effect of the multi-objective optimization problem of Gac oil extraction be possibly applied to determine the technological mode of the extraction in the oil industry.

When the solvent volume of the extraction was fixed: $x_{1}=$ 0.393 , correspondingly $Z_{l}=15.57 \mathrm{ml} / \mathrm{g}$, the relationship between $y_{1}, y_{2}, y_{3}$, and $\mathrm{S}$ combination function with 2 variables $\mathrm{x}_{2}, \mathrm{x}_{3}$ was performed geometrically in $3 \mathrm{D}$ (Fig. 5, 6, $7,8)$. 


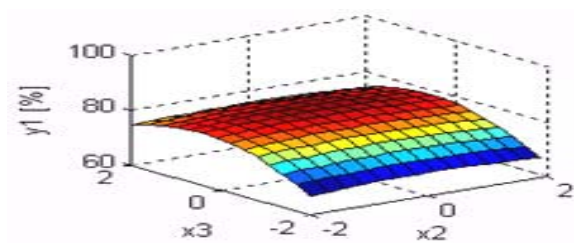

Fig. 6. Extration efficiency, $\mathrm{x} 1=0.393$.

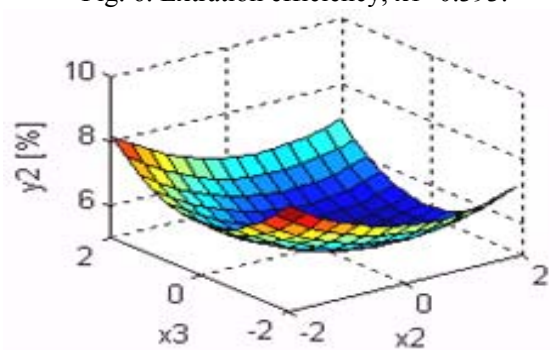

Fig.7. loss of $\beta$-caroten, $\mathrm{x} 1=0.393$.

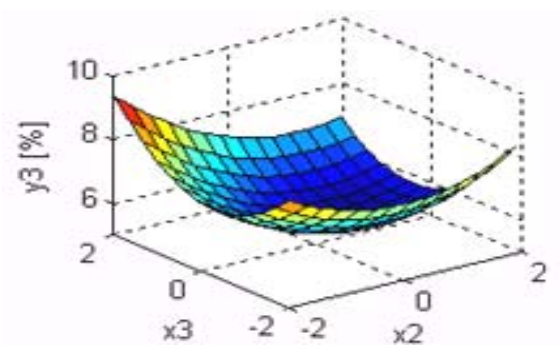

Fig.8. loss of lycopene, $\mathrm{x} 1=0.393$.

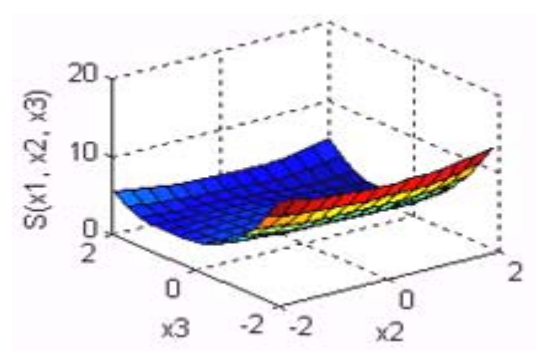

Fig. 9. Function $\mathrm{s}(\mathrm{x} 1, \mathrm{x} 2, \mathrm{x} 3)$, with $\mathrm{x} 1=0.393$.

\section{CONCLUSION}

The mathematical model of regression equations (14), (15), and (16) obtained from the experiments were the experimental statistical models which could well describe the impact of solvent volume, time and temperature on the extraction efficiency, the loss of $\beta$-carotene and the loss of lycopene of the Gac oil from the solvent extraction.

Solving multi-objective optimization problem by the utopian point method determined the optimal technological mode of Gac oil extraction, with the solvent volume of 15.57 $\mathrm{ml} / \mathrm{g}$; the extraction time of 6.056 hours; the extraction temperature of $69.620 \mathrm{C}$, resulting in: the extraction efficiency of $80.02 \%$, the loss of $\beta$-carotene and lycopene of the Gac oil of respectively $5.31 \%$ and $5.68 \%$.

Therefore, the technological mode of the extraction of Gac oil was feasible to be applied to industrial production.

\section{ACKNOWLEDGMENT}

The author thank Ms. Dang Thi Ngoc Dung and Student. Nguyen Thanh Khu, for help with expriments carrying out.

\section{REFERENCES}

[1] H. NTT and T. H Hung (2009). Research determined the chemical composition of Gac Vietnam, University of Industry Ho Chi Minh City, Viet Nam, http://www.vnulib.edu. vn:8000/dspace/handle 123456789/ 1234

[2] K. Betty, I. C. Turner, H. M. Chapman, and A. T. McKeon, (2004). F. Acid, and C. Composition of Gac (Momordica Cochinchinensis Spreng) Fruit, J. Agric. Food Chem, 52(2), pp $274-279$

[3] H. AOKI, N. T. M. Kieu, N. Kuze, K. Tomisaka, and N. V. Chuyen, (2002). Carotenoid Pigments in GAC Fruit (Momordica Cochinchinensis Spreng), Food Color Laboratory Division, Toyonaka, Osaka and Department of Food and Nutrition, Japan Women's University, Tokyo, Japan, Boisci, Biotechnol, Biochem, 66, 2479 2482.

[4] M. Fillon, (2007). Gac the Asian- This "Gift from heaven" Brims with an unsurpassed mix of Antioxidants, Breakthroughs in health, Vol. 2, p15-16, 47-49.

[5] V. L. T, King JC, (2003). A method for preserving gac fruit oil, a good source of $\beta$ carotene and essential fatty acids, Food Nutr Bull, 24, 224-230

[6] H. NV (2006). Research detemined the technology mode of oil extraction from Gac. Journal of Science and Technology 4: 123-136, http://www.vjol.info/index.php/jst/search /results.

[7] H. NH (2008). Research oil extracted from in Gac by extraction method, using acetone solvent, Journal the Development of Science and Technology VNU.HCM 11: 16-24, http://www.vnulib.edu.vn:8000/dspace/handle/123456789/706

[8] D. NT, D. NQ (2011), Application of Multi-Objective Optimization to Determining the Technological Mode of Avocado Oil Extraction. Canadian Journal on Chemical Engineering and Technology, Vol. 2, No. 6, July 2011, ISSN: 1923-1652, p. 106-113

[9] D. NT, D. NQ, D. T. V. and H. LX (2011). Application of Multi-Objective Optimization by $\mathrm{S}$ and $\mathrm{R}$ Optimal Combination Criteria to Determining the Freeze Drying Mode of Penaeus Monodon, Journal of Chemical Engineering and Process Technology, USA 2:107. DOI 10.4172/2157-7048.1000107.

[10] H. L X, and L. N. T (2008). Multi-objective optimization with combination criteria applied to extraction of the high colour degree anthocyanin, Science and Technology development, VNU-Ho Chi Minh City 11: 69-76, http://tailieu.vn/xem-tai-lieu/toi-uu-da-muc-tieu-voi-cac-chuan-toi-uu -to-hop-s-va-r.205116.html

[11] H. N. T, H. D. X, and H. T. V (2006). A method of collective decision-making based on fuzzy data classification: GDM - FC, Journal of Science and Technology 2: 65-74, http://www.hua.edu.vn/tc khktnn/download .asp?ID=241

[12] H. L. X, N. N. V (2008). Multi-objective optimization for grouper (e.coioides) compounded feed formulation, Journal of Science and Technology, VietNam, 48: 123-136, http://www.vjol.info/index.php /jst/ search/results.

[13] N. Canh (2004) Planning experiments (Book), Published by VNU $H C M C$, 3th ed, Viet Nam, 120.

[14] D. N. T, H. L. X, and D. T. V (2010). Multi-objective optimization with optimal standard combination of $\mathrm{R}$ applied to determine regime technological freeze drying of penaeus merguiensis, Journal the Development of Science and Technology VNU.HCM 13: 56-68, http://www.vnulib.edu.vn:8000/dspace/handle/123456789/3614

[15] D. N. T, H. L. X, D. T. V, and B. T. D (2010). Multi-objective optimization applied to determine regime technological freeze drying of penaeus vannamei. Journal of Fisheries Science and Technology, Vietnam 1: 82-93, http://www.vnulib.edu.vn:8000/dspace/handle $/ 123456789 / 3622$

[16] P. T. V (2004), Heat and mass transfer process (Book), Published by $V N U$ HCMC, 2th ed, Viet Nam, 385

[17] S. Khalloufi, J. L. Robert, and Ratti (2004). Solid foods Freeze drying simulation and experimental data, Journal of Food Engineering, Canada 28: 107-132. DOI: 10.1111/j.1745-4530.2005.00379.x

[18] L.O. Figura, A. A Teixeira (2007). Food Physics: Physical properties Measurement and Application, Germany, 554. http://mechmath.org/ books $/ 82246$

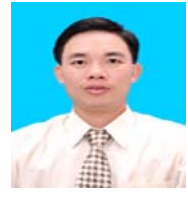

Nguyen Tan Dzung Faculty of Chemical and Food Technology, HCMC University of Technical Education,01-Vo Van Ngan Street, Thu Duc District, Ho Chi Minh City, Viet Nam 